\title{
Emerging role of human factors and ergonomics in healthcare delivery - A new field of application and influence for the IEA
}

\author{
Pascale Carayon ${ }^{\mathrm{a}}$ \\ ${ }^{a}$ Center for Quality and Productivity Improvement and Department of Industrial and Systems Engineering, \\ University of Wisconsin-Madison, 1550 Engineering Drive, Madison WI 53706, USA, carayon@engr.wisc.edu
}

\begin{abstract}
Recent developments of research and application of Human Factors and Ergonomics (HFE) are described, in particular the domain of healthcare delivery. HFE activities in this domain are highlighted and challenges for the discipline and the International Ergonomics Association are presented.
\end{abstract}

Keywords: health care, healthcare delivery, HEPS, patient safety, IEA

\section{HFE in health and health care}

Traditionally when HFE (Human Factors and Ergonomics) research and practice address health and health care, most people think about issues associated with the health of workers and the health problems experienced by healthcare workers. With regard to worker health, HFE typically addresses how work and working conditions can influence the physical and mental health of workers. For instance, HFE has examined extensively the impact of work on musculoskeletal disorders. Recently, HFE has recognized the role of psychosocial work factors in worker health and safety [11]. HFE researchers and practitioners have devised and evaluated various methods for improving working conditions and worker health. With regard to health care, HFE has focused on issues in healthcare work, such as workload, stress and musculoskeletal disorders experienced by nurses. Recent developments of HFE research and application in health and health care expand the role of HFE to improve the delivery and organization of healthcare services and health in general. Improvements in the way healthcare is delivered should lead to health improvement. For instance, the ergonomic design of medical devices can support nurses' safe administration of medications [9]. HFE can make important contributions to this mechanism by helping in the design of health and healthcare technologies, systems and processes.

HFE is increasingly contributing to the design of technologies, systems and processes for improving health in non-work environments. Examples include: design of blood glucose meter for diabetic patients [25], design of health technologies (e.g., medication delivery system) for elderly patients [17], and design of health information management systems to be used by families [32]. Another area of increasing importance for HFE is the recent focus on healthcare delivery. In this paper, we describe HFE contributions in the design and improvement of healthcare delivery technologies, systems and processes.

\section{Healthcare delivery}

The healthcare industry is a major industrial sector in numerous countries. The recent economic recession has contributed to the slowing down of increases in health spending in the US; however, health spending still represents a major proportion of the gross domestic product (GDP): 17.6\% in 2009 in the US [23]. In other industrialized countries, health expenditures represent between $8-11 \%$ of the GDP. Therefore, the healthcare sector plays a major socioeconomic role in many countries. Improving the de- 
livery and organization of healthcare delivery can have major impact not only on patients, but also on the socioeconomic health of countries.

Interest in improving healthcare delivery has steadily increased at national and international levels. A 2008 report by the World Health Organization on "Primary Health Care - Now More than Ever" highlights major problems with healthcare delivery systems across the world: (1) inverse care or inequity between those with the least means and the greatest health problems and those with the most means and lesser health problems; (2) impoverishing care or poverty related to health expenses; (3) fragmented and fragmenting care related to specialization of healthcare providers, narrow focus of many disease control programs and lack of holistic approach to health; (4) unsafe care and medical errors related to poorly designed healthcare systems and processes; and (5) misdirected care and lack of resources dedicated to primary prevention and health promotion. The WHO proposes four sets of reforms for addressing these problems: universal coverage reforms, service delivery reforms, public policy reforms, and leadership reforms. The HFE discipline has a major role to play in service delivery reforms that improve health services around people's needs and expectations, therefore leading to improved health and other outcomes.

A series of reports by the US Institute of Medicine has highlighted major problems related to healthcare delivery, including medical errors [22], medication errors [18], and poorly designed work systems of nurses [20] and medical residents [28]. These reports clearly outline the numerous contributions that HFE can make to improving the design, implementation and use of healthcare systems and processes, therefore, producing better outcomes for all involved, i.e. patients and their families, healthcare professionals and the society at large [19].

Healthcare delivery represents an emergent domain of application for the HFE discipline. In this paper, we describe concepts of healthcare quality and propose ways that HFE can contribute to improving healthcare quality by redesigning systems and processes. We also pose the question of the leadership of HFE in this domain.

\section{Healthcare quality}

The US Institute of Medicine has defined six dimensions of healthcare quality [19]:
(1) safety: "avoiding injuries to patients from the care that is intended to help them"

(2) effectiveness: "avoiding underuse and overuse" of healthcare services

(3) patient-centered care: "providing care that is respectful of and responsive to individual patient preferences, needs, and values and ensuring that patient values guide all clinical decisions"

(4) timeliness: reducing delays in patient care

(5) efficiency: "avoiding waste, including waste of equipment, supplies, ideas, and energy"

(6) equity: "providing care that does not vary in quality because of personal characteristics".

HFE has been at the center of discussion about patient safety: HFE has concepts, theories and methods that can be used and applied to enhance safety and reduce preventable patient harm [2, 4, 13]. Whereas much of the focus of HFE has been on patient safety, it is important to recognize that HFE can contribute to the other dimensions of healthcare quality [7]. For instance, HFE can help to improve patient-centered care by understanding the roles that patients can play in the management and improvement of their own safety [24].

\section{Redesigning healthcare systems and processes}

Given the complexity of healthcare systems and processes, we need to promote HFE systems approaches [30], such as those proposed by Vincent [29], Gopher [15], Bogner [1], Carayon [8], and Karsh [21]. An example of an HFE systems approach to the redesign of healthcare systems and processes is the SEIPS [Systems Engineering Initiative for Patient Safety] model that builds on the macroergonomic work system model of Smith and Carayon [3, 10, 26, 27] and integrates the well-known Structure-ProcessOutcome model of healthcare quality [14].

According to the SEIPS model of work system and patient safety [8], the interactions between work system elements (the people such as patients and healthcare providers, tasks, tools and technologies, physical environment and the organization) influence the way care is delivered, i.e. care processes, which in turn can influence patient outcomes, such as patient safety. Because the SEIPS model is anchored in the HFE discipline, the people are at the center of the work system and the system should be designed to facilitate and support the performance and well-being of the people. In addition, the SEIPS model includes 
two categories of outcomes: patient outcomes (e.g., patient safety) and individual and organizational outcomes (e.g., quality of working life, organizational performance).

HFE research is necessary in numerous healthcare quality areas [7]:

- workload management,

- physical, cognitive and macroergonomic issues of medical devices and health information technologies,

- HFE in transitions of care,

- HFE of patient-centered care,

- risk management and patient safety management,

- resilience, and

- feedback loops between event detection, reporting and analysis and system redesign.

HFE practitioners have also an important role to play in helping healthcare organizations (e.g., hospitals) to use human factors methods and principles in their operations $[5,6]$. HFE practitioners can also help manufacturers of healthcare equipment and technology (e.g., design of health information technology) to integrate user-centered design processes $[5,31]$.

\section{HFE as leader in healthcare quality?}

According to Henriksen [16], "there currently exists a great opportunity... for human factors researchers and practitioners to join with their clinical counterparts to serve in leadership roles and continually expand health care's capacity to generate safe and high quality patient care environments" (page 36). The HFE community's contribution to improvement in healthcare delivery and patient care quality has steadily increased in the past 10 years. The International Ergonomics Association has sponsored a series of triennial conferences on Healthcare Systems Ergonomics and Patient Safety (HEPS). The first HEPS conference was held in 2005 in Firenze, Italy, and was organized by Sebastiano Bagnara, Riccardo Tartaglia, Tommaso Bellandi and Sara Albolino.

We need to do more and better; the HFE community needs to increase its impact on and relevance for health care. We also need to take on a greater leadership role in healthcare quality.

Potential barriers to this increasing role of HFE exist, such as cultural differences between the core systems approach of HFE and values and beliefs in health care [12]. These "cross-cultural" barriers be- tween HFE and health care can be resolved by providing high-quality HFE training to healthcare professionals, and helping healthcare professionals to become 'biculturals' in HFE and their health science (e.g., medicine, nursing, pharmacy) [5, 12]. If HFE innovations are going to be adopted by healthcare organizations, the national and international HFE community needs to improve the dissemination of its HFE knowledge, and create HFE tools, methods and models that can help to address the challenging and complex healthcare quality problems.

We should partner with key national and international organizations that are active in healthcare quality to improve the delivery of health care across the world.

\section{Acknowledgments}

This publication was partially supported by grant 1UL1RR025011 from the Clinical \& Translational Science Award (CTSA) program of the National Center for Research Resources National Institutes of Health [PI: M. Drezner].

\section{References}

[1] M.S. Bogner, The artichoke systems approach for identifying the why of error, in: Handbook of Human Factors in Health Care and Patient Safety, P. Carayon, Ed., ed, Lawrence Erlbaum, Mahwah, NJ, 2007, pp. 109-126.

[2] M.S. Bogner, Ed., Human Error in Medicine, Lawrence Erlbaum Associates, Hillsdale, NJ, 1994.

[3] P. Carayon, The Balance Theory and the work system model... Twenty years later, International Journal of HumanComputer Interaction 25 (2009), 313-327.

[4] P. Carayon, Ed., Handbook of Human Factors in Health Care and Patient Safety, Lawrence Erlbaum Associates, Mahwah, New Jersey, 2007.

[5] P. Carayon, Human factors in patient safety as an innovation, Applied Ergonomics 41 (2010), 657-665.

[6] P. Carayon, Top management's view on human factors and patient safety: Do they see it?, in: Healthcare Systems Ergonomics and Patient Safety, R. Tartaglia, et al., Eds., ed, Taylor \& Francis, Florence, Italy, 2005, pp. 38-42.

[7] P. Carayon, E.J. Bass, T. Bellandi, A.P. Gurses, M.S. Hallbeck, and V. Mollo, Socio-technical systems analysis in health care: A research agenda, IIE Transactions on Healthcare Systems Engineering (2011).

[8] P. Carayon, A.S. Hundt, B.-T. Karsh, A.P. Gurses, C.J. Alvarado, M. Smith, and P.F. Brennan, Work system design for patient safety: The SEIPS model Quality \& Safety in Health Care 15 (2006), i50-i58.

[9] P. Carayon, A.S. Hundt, and T.B. Wetterneck, Nurses' acceptance of Smart IV pump technology, International Journal of Medical Informatics 79 (2010), 401-411. 
[10] P. Carayon and M.J. Smith, Work organization and ergonomics, Applied Ergonomics 31 (2000), 649-662.

[11] P. Carayon, M.J. Smith, and M.C. Haims, Work organization, job stress, and work-related musculoskeletal disorders, Human Factors 41 (1999), 644-663.

[12] P. Carayon and A. Xie, Decision making in healthcare system design: When human factors engineering meets health care, in: Cultural Factors in Decision Making and Action, R.W. Proctor, et al., Eds., ed, Taylor \& Francis, 2011.

[13] R.I. Cook, D.D. Woods, and C. Miller, A Tale of Two Stories: Contrasting Views of Patient Safety, National Patient Safety Foundation, Chicago, IL, 1998.

[14] A. Donabedian, The quality of medical care, Science 200 (1978), 856-864

[15] D. Gopher, Why is it not sufficient to study errors and incidents: Human factors and safety in medical systems, Biomedical Instrumentation \& Technology 38 (2004), 387409.

[16] K. Henriksen, Human factors and patient safety: Continuing challenges, in: Handbook of Human Factors and Ergonomics in Health Care and Patient Safety, P. Carayon, Ed., ed, Lawrence Erlbaum Associates, Mahwah, NJ, 2007, pp. 21-37.

[17] O.K. Hernandez, C.M. Sommerich, and D.D. Woods, Telepresence as an aid for medication self-management, Ergonomics in Design 19 (2011), 15-23.

[18] Institute of Medicine, Preventing Medication Errors, The National Academies Press, Washington, DC, 2006.

[19] Institute of Medicine Committee on Quality of Health Care in America, Crossing the Quality Chasm: A New Health System for the 21st Century, National Academy Press, Washington, DC, 2001.

[20] Institute of Medicine Committee on the Work Environment for Nurses and Patient Safety, Keeping Patients Safe: Transforming the Work Environment of Nurses, The National Academies Press, Washington, D.C., 2004.

[21] B.-T. Karsh, R.J. Holden, S.J. Alper, and C.K.L. Or, A human factors engineering paradigm for patient safety: Designing to support the performance of the healthcare professional, Quality \& Safety in Health Care 15 (2006), i59i65.

[22] L.T. Kohn, J.M. Corrigan, and M.S. Donaldson, Eds., To Err is Human: Building a Safer Health System, National Academy Press., Washington, D.C., 1999.

[23] A. Martin, D. Lassman, L. Whittle, and A. Catlin, Recession contributes to slowest annual rate of increase in health spending in five decades, Health Affairs 30 (2011), 11-22.

[24] V. Mollo, A. Pernet, G. Moutel, N. Giraud, and P. Giraud, Le patient peut-il et doit-il participer à la gestion des risques en radiothérapie ?, Cancer/radiothérapie (2011), 176-181.

[25] A.L. Mykityshyn, A.D. Fisk, and W.A. Rogers, Learning to use a home medical device: Mediating age-related differences with training, Human Factors 44 (2002), 354-364.

[26] M.J. Smith and P. Carayon-Sainfort, A balance theory of job design for stress reduction, International Journal of Industrial Ergonomics 4 (1989), 67-79.

[27] M.J. Smith and P. Carayon, Balance theory of job design, in: International Encyclopedia of Ergonomics and Human Factors, W. Karwowski, Ed., ed, Taylor \& Francis, London, 2000, pp. 1181-1184.

[28] C. Ulmer, D.W. Wolman, and M.E. Johns, Eds., Resident Duty Hours: Enhancing Sleep, Supervision, and Safety, The National Academies Press, Washington, DC, 2008.

[29] C. Vincent, K. Moorthy, S.K. Sarker, A. Chang, and A.W Darzi, Systems approaches to surgical quality and safety From concept to measurement, Annals of Surgery 239 (2004) $475-482$.

[30] P. Waterson, A critical review of the systems approach within patient safety research, Ergonomics 52 (2009), 11851195.

[31] M.B. Weinger, M. Wiklund, and D.J. Gardner-Bonneau, Eds., Handbook of Human Factors in Medical Device, Taylor \& Francis, Boca Raton, FL, 2011.

[32] T. Zayas-Caban and B.E. Dixon, Considerations for the design of safe and effective consumer health IT applications in the home, Quality \& safety in health care 19 Suppl 3 (2010), i61-67. 